\title{
Calculation of the Roadside Clear Zone Width along Highways Based on the Safe Slope
}

\author{
Rui Cheng $\left(\mathbb{D},{ }^{1}\right.$ Guozhu Cheng $\mathbb{D}^{1},{ }^{1}$ Yulong Pei $\mathbb{D}{ }^{1}$, and Liang Xu $\mathbb{D D}^{2}$ \\ ${ }^{1}$ School of Traffic and Transportation, Northeast Forestry University, Harbin 150040, China \\ ${ }^{2}$ School of Civil Engineering, Changchun Institute of Technology, Changchun 130012, China \\ Correspondence should be addressed to Guozhu Cheng; guozhucheng@126.com
}

Received 5 March 2021; Revised 5 May 2021; Accepted 24 May 2021; Published 8 June 2021

Academic Editor: Guohui Zhang

Copyright (c) 2021 Rui Cheng et al. This is an open access article distributed under the Creative Commons Attribution License, which permits unrestricted use, distribution, and reproduction in any medium, provided the original work is properly cited.

International crash data indicate that roadside characteristics contribute to more than half of all roadside accidents involving serious injury or death. Therefore, research on roadside safety is urgently needed. Based on the vehicle departure speed, pavement height (i.e., the difference between pavement elevation and ground elevation), slope gradient, and horizontal curve radius, this study uses PC-Crash simulation software to carry out tests of trucks and cars exiting a road. A chi-squared automatic interaction detection (CHAID) decision tree is used to explore the causative mechanism of vehicle rollover, and the concept of a "safe slope" to ensure that vehicles do not roll over is proposed. Aiming at straight and curved sections, discriminant functions of vehicle rollover and nonrollover are fitted through Bayesian discriminant analysis, and safe slope calculation models for trucks and cars are then constructed. Based on the obtained safe slope models, calculation methods for the safe slope and the roadside clear zone width involving different traffic compositions are proposed by calibrating the lateral distance from the final position of nonrollover vehicles to the road edge. The results show that the factors affecting vehicle rollover are, in descending order of importance, the slope gradient, pavement height, vehicle type, departure speed, and horizontal curve radius. For a section with a large proportion of cars, the slope gradient should not be steeper than 1:3.5. The horizontal curve radius should not be less than $600 \mathrm{~m}$ for a section with a large proportion of trucks and a slope gradient steeper than 1:3.5 or shallower than 1:2.5. Additionally, for a section with a pavement higher than $0.5 \mathrm{~m}$ and a slope gradient steeper than $1: 2.5$, the operating speed limit should be lower than $60 \mathrm{~km} / \mathrm{h}$. These research results have theoretical value and practical significance to improve the driving safety level and reducing the risk of roadside accidents.

\section{Introduction}

According to the Roadside Safety Research Program of the Federal Highway Administration (FHWA), roadside accidents account for more than $50 \%$ of all traffic fatalities [1]. A European survey showed that roadside accidents account for $19 \%, 19 \%$, and $22 \%$ of all traffic accidents in Germany, Greece, and Austria, respectively, but account for 33\%, 34\%, and $36 \%$ of the total traffic accident deaths [2]. According to China's Road Traffic Accident Statistics Annual Report, roadside accidents account for approximately $8 \%$ of the total number of annual accidents in China but cause 13\% of all traffic accident deaths [3]. Compared with other accident types, the high fatality rate associated with roadside accidents indicates that relevant research on roadside safety is urgently needed.

Compared with other measures, the roadside clear zone (RCZ) has great significance in improving roadside safety. According to the definition of the RCZ in the fourth edition of the Roadside Design Guide (RDG) [4], the RCZ should provide a fault-tolerant space with sufficient width for outof-control vehicles, and this area should have a gentle slope and no obstacles. Researchers in academia have long been concerned with determining the slope and width of the RCZ 
based on different regional characteristics, road characteristics, and traffic conditions to ensure that roadside accidents pose the minimum possible risk.

With regard to the roadside slope, Zeeger et al. proposed that rollover accidents could be reduced by $27 \%$ by adjusting the slope from 1:2 to 1:7 or an even shallower gradient [5]. A subsequent study showed that the roadside slope has significant effects on single-vehicle accidents. For example, reducing the roadside slope from 1:3 to 1:7 or a flatter gradient steadily reduced the accident rate; the accident rate will hardly be affected if the roadside slopes range from 1:2 to 1:3; and a roadside slope of 1:5 is effective in reducing the traffic accident rate [6]. The fourth edition of the $R D G$ provides a standard setting for the slope gradient in the RCZ, as shown in Figure 1 [4]. A vehicle on a slope equal to or shallower than 1:4 is considered recoverable, whereas a vehicle on a slope between 1:3 and 1:4 is considered unrecoverable. In addition, when the roadside is not equipped with conditions for setting a recoverable slope, additional clear runout areas can be set at the foot of the unrecoverable slope to reduce the risk posed by out-of-control vehicles, and the slope gradient in this area should be equal to or shallower than 1:6.

In terms of the RCZ width, the fourth edition of the $R D G$ suggests the value for a straight section. This value is determined by the design speed, average daily traffic volume, slope form, and slope gradient and provides the correction coefficient for a curved section, which is selected based on the horizontal curve radius [4]. These research results are now widely used around the world. Considering that the suggested width is based on limited empirical data, although such data provide a reference for roadside safety design during highway construction in most countries, there are significant differences in road network characteristics, vehicle ownership, driving behavior, roadside barrier distributions, and socioeconomic level. Thus, researchers must adjust the $R D G$ measures to local conditions to develop research on the RCZ width based on national conditions.

For example, by analyzing the main factors affecting the design width of an RCZ, including the driver reaction time, the state of vehicles exiting the road, and the distance traveled by vehicles, Fan and Xing established an RCZ width calculation model and presented a recommended RCZ width, but the model basically assumes that the slope is flat, which is inconsistent with the actual situation [7]. Referring to the fourth edition of the RDG, China's Specifications for Highway Safety Audit (JTG B05-2015) divide the RCZ width into computed and actual values and provide a graphical method for calculating the RCZ width for a straight section based on operating speed and one-way annual average daily traffic (AADT). Based on this, the RCZ width for a curved section is chosen by adjusting the coefficient on the diagram according to the horizontal curve radius and operating speed. Additionally, the slope gradient that offers the effective RCZ width is specified (i.e., when the slope gradient is shallower than 1:6, the effective RCZ width is the whole slope surface width; when the slope gradient is between 1:3.5 and $1: 6$, the effective RCZ width is half of the slope surface width; and when the slope is steeper than 1:3.5, there is no effective RCZ width) [8].
In terms of the relationship between the RCZ width and roadside accident risk, Australian researchers reported that an RCZ width of at least $2 \mathrm{~m}$ could significantly reduce the consequences of vehicles leaving the road [9]. Sax et al. proposed that a clear zone width of 4-5 feet on the roadside could reduce $90 \%$ of accidents involving a collision with an obstacle [10]. A study from England showed that with an increase in RCZ width, the number of roadside accidents gradually decreased [11]. Turner and Barnett found that approximately $90 \%$ of accidents occurred within 10 feet of the road edge, and the number of accidents showed a linear relationship with the distance [12]. Maze et al. analyzed the relationship between vehicle collisions and RCZ width in Iowa and found that approximately $90 \%$ of all collisions with objects occurred in the RCZ within 5 feet of the road edge, and approximately $90 \%$ of the economic loss was incurred by collisions in the RCZ within 3 feet of the road edge [13]. McLean showed a diminishing returns relationship between the safety benefits and width of an RCZ, and the safety benefits of RCZs of 6-9 m wide exceeded 85\% [14]. However, the research of Jurewicz and Pyta showed that a large number of roadside accidents still occurred in an RCZ with a width of 29.5 feet [15]. For this reason, in a study on driver behavior, Fitzpatrick et al. combined two variables, the RCZ width and the density of roadside vegetation, and explored their influences on driver behavior in terms of speed and lateral position. The results showed that the wider the RCZ was, the faster the driving speed; moreover, as the width of the RCZ increased, drivers tended to drive closer to the road edge $[16,17]$.

By examining the results of RCZ research, Table 1 presents various research methods and the corresponding literature output, researcher, publication year, and research topic. The research methods include mainly accident statistics, graphical methods, driving simulations, and formula derivations. To date, accident statistics are the most widely used. By collecting a large number of roadside accidents and using various statistical regression models (such as the multiple logit, latent class, mixed logit, and ordered logit/ probit models), this method explores the relationship between various roadside features and accident risk and identifies significant risk factors influencing accident severity. Although the conclusions provide guidance for improving the roadside design, such as increasing the offset distance of poles, trees, and other obstacles and reducing the side slope gradient and subgrade height, these studies are mostly qualitative analyses and do not estimate a safe threshold or standard to ensure a lower accident risk. Taking the fourth edition of the $R D G$ as an example, the graphical method can visually show how to determine the RCZ width by considering the design speed, AADT, slope form, and slope gradient. However, this method has the following problems: (1) the AADT is related to the probability of roadside accidents but should not be applied as the basis for determining the RCZ width; (2) the influences of the vehicle type, presence of a shoulder, and adhesion coefficient are not considered; (3) the effectiveness of the graphical method is limited, which hinders the accurate calculation of RCZ width; and (4) the quantitative relationship between the 


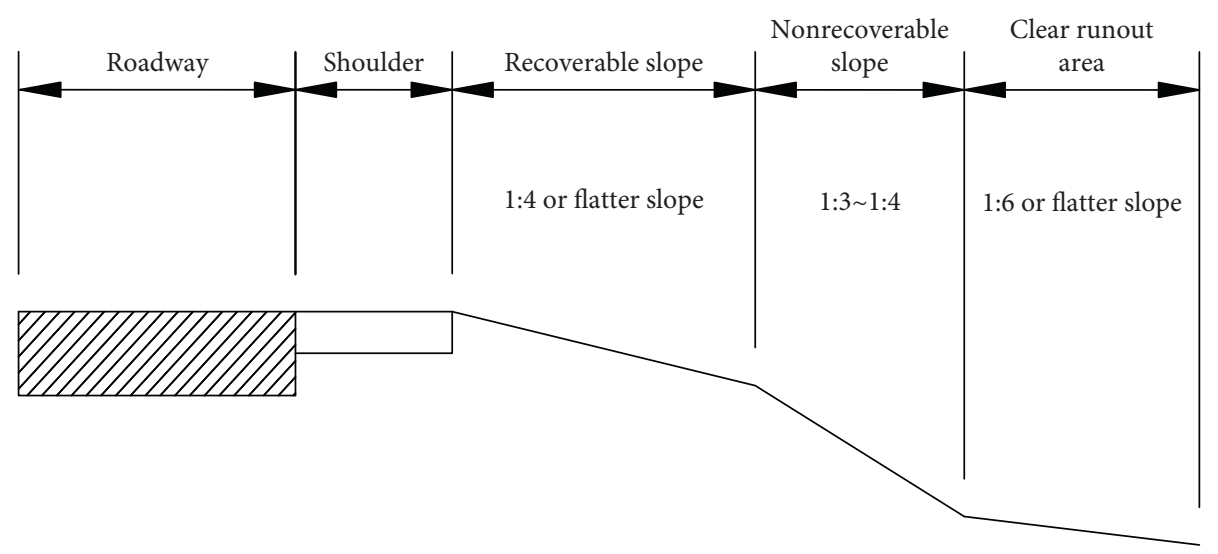

FIgURE 1: Standard setting of the roadside slope.

TABLE 1: Statistical results.

\begin{tabular}{|c|c|c|c|}
\hline Method & Output & Researchers (publication year) & Research topic \\
\hline $\begin{array}{l}\text { Accident } \\
\text { statistics }\end{array}$ & 19 & $\begin{array}{l}\text { Ogden (1996); Ayati (2007); Sax (2010); Jurewicz (2010); MDOT (2011); Albuquerque (2011) } \\
\text { Zeeger (1987); Zeeger (1992); Roque (2015) } \\
\text { Donnell (2006); Liu (2009, 2011); Doecke (2011); Johnson (2015); Roque (2018); Park (2016); } \\
\text { Li (2018, 2019); Yu (2019) }\end{array}$ & $\begin{array}{l}\text { RCZ width } \\
\text { Roadside slope } \\
\text { Roadside } \\
\text { barrier }\end{array}$ \\
\hline $\begin{array}{l}\text { Graphical } \\
\text { method }\end{array}$ & 7 & $\begin{array}{c}\text { Turner (1989); AASHTO }(1996,2002,2006,2011) ; \text { MTPRC (2015) } \\
\text { AASHTO }(1996,2002,2006,2011) ; \text { MTPRC (2015) } \\
\text { Ayati }(2007)\end{array}$ & $\begin{array}{l}\text { RCZ width } \\
\text { Roadside slope } \\
\text { Roadside } \\
\text { barrier }\end{array}$ \\
\hline $\begin{array}{l}\text { Driving } \\
\text { simulation }\end{array}$ & 2 & Fitzpatrick $(2014,2016)$ & RCZ width \\
\hline $\begin{array}{l}\text { Formula } \\
\text { derivation }\end{array}$ & 1 & Fan (2013) & RCZ width \\
\hline
\end{tabular}

effective RCZ width and the slope gradient is not expressed, and the determination of the actual RCZ width is not sufficiently accurate. Driving simulations focus primarily on the influence of the RCZ on a driver's behavior, for example, by exploring the influence of RCZ width and the density of roadside vegetation on vehicle speed and lateral position, the motion state of a vehicle entering the RCZ cannot be simulated because the simulator does not allow the vehicle to run off the road. By analyzing the driver reaction time, the state of vehicles exiting the road, and the distance traveled by vehicles, an RCZ width calculation model is built by formula derivation. In view of the complexity and uncertainty of the transportation environment, this method is limited to the theoretical level, which is of little significance in guiding engineering practices.

In summary, the existing RCZ design methods are insufficiently comprehensive with regard to the influencing factors, and the accuracy of quantitative calculation is inadequate. Thus, for sections with a limited area, a high subgrade, and a steep roadside slope, considering the rollover risk of vehicles after running off the road, this paper proposes a concept of a "safe slope" - that is, a slope on which out-of-control vehicles cannot return to the road but will not roll over. PC-Crash simulation software is employed to carry out tests on trucks and cars exiting the road at different departure speeds, pavement heights, slope gradients, and horizontal curve radii. PC-Crash is a computer simulation software program developed by Austrian scholars and is widely used throughout the world for the simulation and reconstruction of traffic accidents. With powerful functions and simple operations, this software can overcome the limitations of the above research methods. For example, (1) it allows vehicles to enter the roadside; (2) it contributes to achieving quantitative and accurate calculation of RCZ width based on the assigned variables and distance calibration function; and (3) it is widely used in forensic identification and liability determination of traffic accidents, so it can recreate the accident process more realistically. Moreover, a large number of studies have proven that PC-Crash software has high accuracy in simulating rollover accidents [18-20].

By recording vehicle motion states (rollover or nonrollover) and motion tracks, a chi-squared automatic interaction detection (CHAID) decision tree is used to explore the causative mechanism of rollover for vehicles. Safe slope calculation models corresponding to different operating speeds, pavement heights, and horizontal curve radii for trucks and cars are constructed for straight and curved sections of roads by fitting a Bayesian discriminant function of vehicle rollover and nonrollover. Based on the obtained 
safe slope models, by calibrating the lateral distance from the final position of vehicles to the road edge, multiple regression analysis is applied to fit the calculation models of RCZ width for trucks and cars to quantitatively calculate the precise RCZ width and safe slope gradient. Finally, calculation methods for the safe slope and the RCZ width for different traffic compositions are proposed by introducing the proportion of trucks.

\section{Data and Methods}

2.1. Data. According to our experience in roadside accident investigations, the factors affecting the motion state and motion track of vehicles exiting the road include primarily the departure speed, departure angle, braking response time, pavement height, slope gradient, road adhesion coefficient, slope adhesion coefficient, and horizontal curve radius. Therefore, the value of each factor should be discussed and determined.

Based on the relevant regulations of China's Design Specification for Highway Alignment (JTG D20-2017) [21], the departure speed, horizontal curve radius, slope gradient, pavement height, and vehicle type values in this simulation test are shown in Table 2.

Many factors determine the angle at which a vehicle leaves the road, and most drivers will turn the steering wheel immediately upon recognizing danger. However, the influence of these factors on the departure angle is uncertain and difficult to quantify. Therefore, the actual departure angle is highly random and uncertain, and a better way to analyze the departure angle is through case statistics and analysis. Since there is no relevant research in China, we refer to the statistics of actual roadside accidents in the European RISER project [2], which reveal a close relationship between the vehicle departure angle and the departure speed, as shown in Figure 2. The departure angles corresponding to different departure speeds can be approximately estimated through the fitting curve in Figure 2, as shown in Table 3.

Regarding braking response time, by testing the driver's decision time, a previous study proposed that approximately 1.0 s represents $95 \%$ of the driver's decision time; subsequently, it takes approximately $0.2 \mathrm{~s}$ for the driver's right foot to move from the accelerator pedal to the brake pedal upon recognizing danger and approximately $0.1 \mathrm{~s}$ from the moment when the brake pedal is pressed to the moment when the vehicle begins braking [22]. Therefore, the braking response time is approximately $1.3 \mathrm{~s}$. Regarding the road adhesion coefficient and slope adhesion coefficient, considering that the road surface is generally paved with asphalt and the slope surface is mostly covered by vegetation, the relevant regulations in the Identification of the Speed of Vehicles Involved in Road Traffic Accidents (GB/T 33195-2016) [23], the road adhesion coefficient and slope adhesion coefficient are set as 0.7 and 0.55 , respectively.

To improve the reliability of the research results, before the simulation test, we selected a case of a roadside accident to calibrate the simulation scene of the PC-Crash software. The accident section is a two-way four-lane road with a lane
TABLE 2: Test variables.

\begin{tabular}{lcccccc}
\hline Variable & \multicolumn{7}{c}{ Value } \\
\hline $\begin{array}{l}\text { Departure speed }(\mathrm{km} / \mathrm{h}) \\
\text { Horizontal curve radius }\end{array}$ & 40 & 60 & 80 & 100 & 120 \\
$(\mathrm{~m})$ & $+\infty$ & 600 & 500 & 400 & 300 & 200 \\
& $1:$ & $1:$ & $1:$ & $1:$ & $1:$ & $1:$ \\
Slope gradient & 6.5 & 5.5 & 4.5 & 3.5 & 2.5 & 1.5 \\
Pavement height (m) & 0.5 & 2.5 & 4.5 & 6.5 & 8.5 & 10.5 \\
Vehicle type & "Truck" $=1$ & \multicolumn{7}{c}{ "Car" $=0$} \\
\hline
\end{tabular}

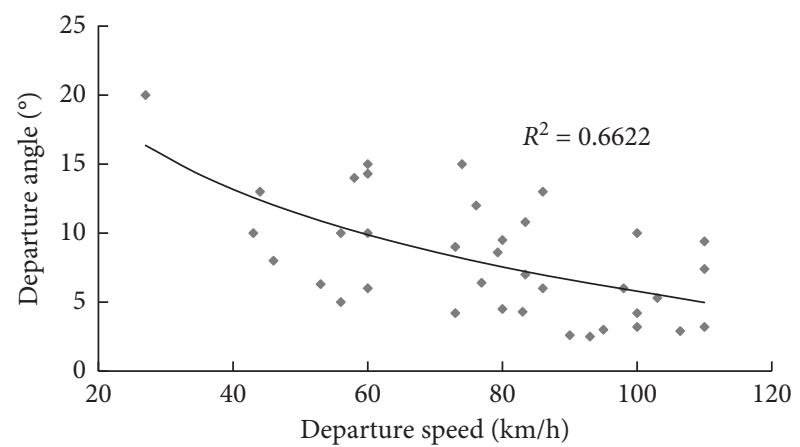

FIgURE 2: Relationship between departure speed and departure angle.

TABle 3: Departure angle.

\begin{tabular}{lccccccccc}
\hline Variables & \multicolumn{10}{c}{ Value } \\
\hline Departure speed $(\mathrm{km} / \mathrm{h})$ & 40 & 50 & 60 & 70 & 80 & 90 & 100 & 110 & 120 \\
Departure angle $\left(^{\circ}\right)$ & 12 & 10 & 9 & 8 & 7 & 6 & 5 & 5 & 4 \\
\hline
\end{tabular}

width of $3.75 \mathrm{~m}$, a shoulder width of $3 \mathrm{~m}$, a horizontal curve radius of $600 \mathrm{~m}$, a slope gradient of $9.5^{\circ}$, a pavement height of $0.7 \mathrm{~m}$, dry asphalt pavement, and a slope covered with vegetation. According to traces at the accident scene, the departure angle of the vehicle was approximately $6^{\circ}$, and the departure distance was approximately $44.3 \mathrm{~m}$. These findings, combined with the driver's confession, indicate that the vehicle speed was approximately $90 \mathrm{~km} / \mathrm{h}$. After the vehicle entered the roadside, the driver braked and took a slight left turn, as shown in Figure 3(a). PC-Crash software is first used to construct the road model, and various road parameters are set according to the characteristics of the accident section, with the adhesion coefficients of the road and slope set as 0.7 and 0.55 , respectively. Subsequently, the test vehicle conforming to the accident vehicle is selected from the simulation software, and the speed, departure angle, braking, and steering of the test vehicle are set according to the accident information, with the braking response time set as $1.3 \mathrm{~s}$. Finally, the simulation results show that the departure distance of the test vehicle is approximately $44.5 \mathrm{~m}$, and its stop position and pose are basically consistent with those of the accident vehicle (as shown in Figure 3(b)). The effectiveness of the simulation scene is therefore verified.

According to the calibrated simulation scene, a BMW $116 \mathrm{~d}$ and ASCHERSLEBEN KAROSS are selected as representative models to collect test data for cars and trucks, 


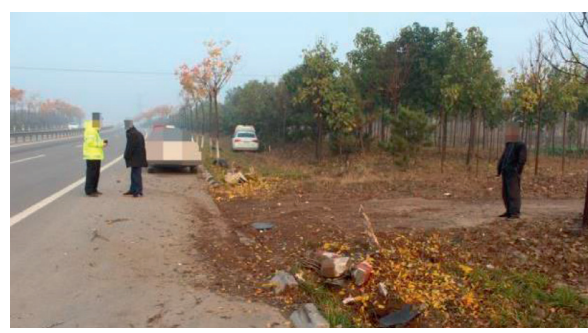

(a)

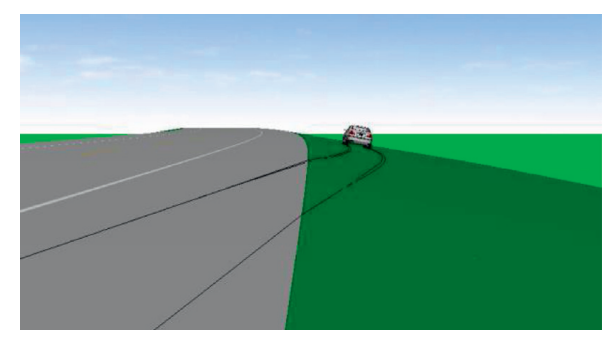

(b)

Figure 3: Simulation calibration: (a) accident scene and (b) simulation scene.

respectively, and their parameters are shown in Table 4 . The initial position of the vehicle is set at the edge of the lane, and the simulation motion sequence module is applied to set the initial speed of the vehicle and implement full braking. The departure angle is calculated according to Table 3. Additionally, considering that the maximum width of the RCZ is required in the condition of a vehicle traveling in a straight line after entering the roadside, we assume that the driver does not take a turn after entering the roadside.

According to the values of the test variables in Table 2, 20 combinations of the slope gradient and pavement height are selected. By setting 6 horizontal curve radii and applying 5 departure speeds (accompanied by the corresponding departure angles in Table 3 ) to 2 vehicle types (i.e., trucks and cars), a total of $20 \times 6 \times 5 \times 2=1,200$ groups of simulation data are obtained, and 1,157 groups of effective data are extracted, including 160 groups on a straight section and 997 groups on a curved section. In the test process, both rollover and nonrollover motion states occur when vehicles exit the road, as shown in Figure 4.

2.2. Decision Tree. As a data mining technology, a decision tree can filter key information from a large number of data samples. As this technology features the multibranch segmentation of data, the initial data nodes are divided into as many subgroups as possible $[24,25]$. To determine the optimal segmentation, a chi-squared independence test is used to detect each grouping rule, and the $p$ value adjusted by the Bonferroni method is used as the segmentation criterion. The smaller the $p$ value is, the better the segmentation [26, 27].

This paper sets the sample group of data as 10 for crossvalidation and builds a tree model using the exhaustive CHAID algorithm, which checks for all possible data groupings. To avoid the infinite growth of the tree model, the grouping level is set as 3. In addition, to reduce the potential for imbalanced data samples, the misclassification cost ratio is set as 100:1 to ensure that the algorithm can achieve more accurate classification and identification of vehicle rollover factors [28].

2.3. Bayesian Discriminant Analysis. Bayesian discriminant analysis operates by dividing data into several categories or a number of known categories, summarizing the rules of discrimination from a large number of data samples, establishing accurate and effective discriminant functions, and classifying the data of unknown categories [29].

When $A_{1}, A_{2}, A_{3}, \ldots, A_{m}$ are set as $m$ categories, the corresponding probability density functions are $f_{1}(x), f_{2}(x)$, $\ldots, f_{m}(x)$. Assuming the prior probabilities of these $m$ categories are $p_{1}, p_{2}, \ldots, p_{m}$, when a sample $x$ is classified, the Bayesian probability formula is used to calculate the posterior probability of $x$ from category $i[30,31]$ :

$$
P\left(\frac{i}{x}\right)=\frac{p_{i}(x) f(x)}{\sum_{i=1}^{m} p_{i}(x) f(x)}, \quad i=1,2, \ldots, m,
$$

where $f(x)$ is the probability density function and $p_{i}(x)$ is the prior probabilities of $x$ from category $i$.

If $P(i / x)=\max _{1 \leq i \leq m} P(u / x), x$ is classified in category $u$, since the probability density function of each category is usually unknown, it is generally assumed that the data sample obeys a multivariate normal distribution and that the covariance matrix of each category is the same. The probability density function of a multivariate normal distribution of category $i$ is then [32]

$$
f_{i}(x)=\frac{1}{\left(2 \pi\left|\sum_{i}\right|\right)^{(1 / 2)}} \exp \left[-\frac{1}{2}\left(x-\mu^{(i)}\right)^{\prime} \sum_{i}^{-1}\left(x-\mu^{(i)}\right)\right],
$$

where $\mu^{(i)}$ is the mean vector of category $i$ and $\Sigma_{i}$ is the covariance matrix of category $i$.

The purpose of Bayesian discrimination is to identify category $i$ of sample $x$ to maximize $P(i / x)$. According to formula (1), the $P(i / x)$ values of different categories primarily depend on the numerator-namely, $P_{i}(x) f(x)$-and are independent of the denominator. Therefore, instead, $i$ should be determined to maximize $P_{i}(x) f(x)$. Both sides of (2) are multiplied by $P_{i}(x)$, and a logarithmic operation is performed. The simplified equivalent discriminant function is as follows:

$$
E_{i}(x)=\ln p_{i}-\frac{1}{2}\left(x-\mu^{(i)}\right)^{\prime} \sum^{-1}\left(x-\mu^{(i)}\right),
$$

where $p_{i}$ is the prior probabilities of category $i$.

Therefore, the discrimination problem becomes $E_{i}(x)=\max _{1 \leq i \leq m} P(u / x)$, where $x$ can be classified in category $u$. 
TABLE 4: Vehicle parameters.

\begin{tabular}{lcc}
\hline Parameter & Car & Value \\
& Truck \\
\hline Length (m) & 4.325 & 6.370 \\
Width (m) & 1.765 & 2.500 \\
Height (m) & 1.420 & 3.100 \\
Wheelbase (m) & 2.690 & 3.700 \\
Weight (kg) & 1385 & 7200 \\
Height of the center of gravity (m) & 0.450 & 1.200 \\
Distance of height of the center of gravity from front axle (m) & 1.210 & 1.070 \\
Tire pattern & 215/50R $16(621 \mathrm{~mm})$ & $7.50 \mathrm{R}$ 16 (719 mm) \\
ABS & Yes & Yes \\
ESP & Yes & No \\
\hline
\end{tabular}

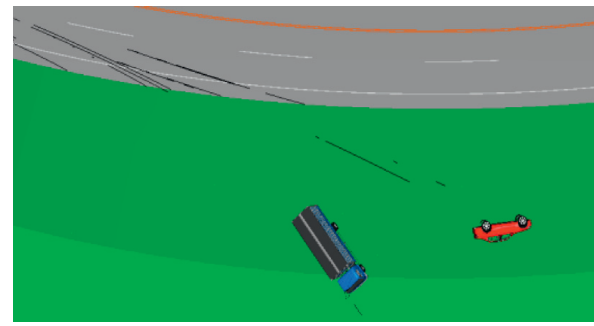

(a)

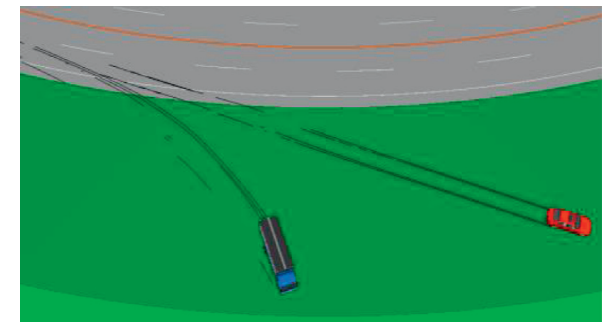

(b)

FIgURE 4: Vehicle motion states: (a) rollover and (b) nonrollover.

\section{Results and Discussion}

3.1. Causative Mechanism of Vehicle Rollover. A CHAID decision tree is used to classify and recognize the simulation data, and the final classification accuracy is $95.3 \%$. In addition, the $p$ value in each node is $0.001<0.05$ (significance level), which indicates an accurate classification with no overfitting. All the data samples are divided into 14 child nodes by different branches, and each child node provides the percentage values of the vehicle under both motion states, as shown in Figure 5, where "No" indicates that no rollover occurs and "Yes" indicates that rollover occurs.

According to the classification rules generated by the tree model, the causative mechanism responsible for vehicle rollover after exiting the road is analyzed, and the main conclusions are drawn as follows:

(1) Node 4 shows that when the slope gradient is shallower than 1:3.5, the car does not roll over. Therefore, for a section with a large proportion of cars, the slope gradient should not be steeper than 1: 3.5 .

(2) According to nodes 4, 5, 6, and 7, in the same test environment, when exiting the road, a truck is more likely to roll over than a car owing to the higher center of gravity of the truck.

(3) Nodes 10, 11, and 12 show that when the slope gradient is steeper than $1: 3.5$ and shallower than 1 : 2.5 and the radius of the circular curve is greater than $600 \mathrm{~m}$, the truck does not roll over. Therefore, the horizontal curve radius should not be less than $600 \mathrm{~m}$ for a section with a large proportion of trucks, and the slope gradient should be steeper than 1:3.5 and shallower than 1:2.5.

(4) Nodes 13 and 14 show that when the departure speed is less than $60 \mathrm{~km} / \mathrm{h}$, the proportion of vehicles that will roll over is $55.1 \%$, and when the departure speed is greater than $60 \mathrm{~km} / \mathrm{h}$, the proportion is as high as 97.1\%. Therefore, for sections with a pavement higher than $0.5 \mathrm{~m}$ and a slope gradient steeper than 1: 2.5 , the recommended operating speed limit is below $60 \mathrm{~km} / \mathrm{h}$. However, if this speed limit is applied to all sections with the above roadside characteristics, it will greatly reduce capacity. Therefore, in certain sections with high-speed limits, alternative measures, such as installing roadside barriers to block vehicles, posting warning signs to remind people to drive carefully, or laying speed bumps, can be proposed.

In addition, according to the results of the decision tree analysis, Figure 6 shows the importance of each test variable to the tree model; the factors affecting vehicle rollover are, in descending order of importance, the slope gradient, pavement height, vehicle type, departure speed, and horizontal curve radius.

3.2. Discriminant of Vehicle Motion States. Considering that the slope gradient is the most important factor affecting vehicle rollover, this paper proposes the concept of a safe slope for sections with a limited area and high subgrade, that 


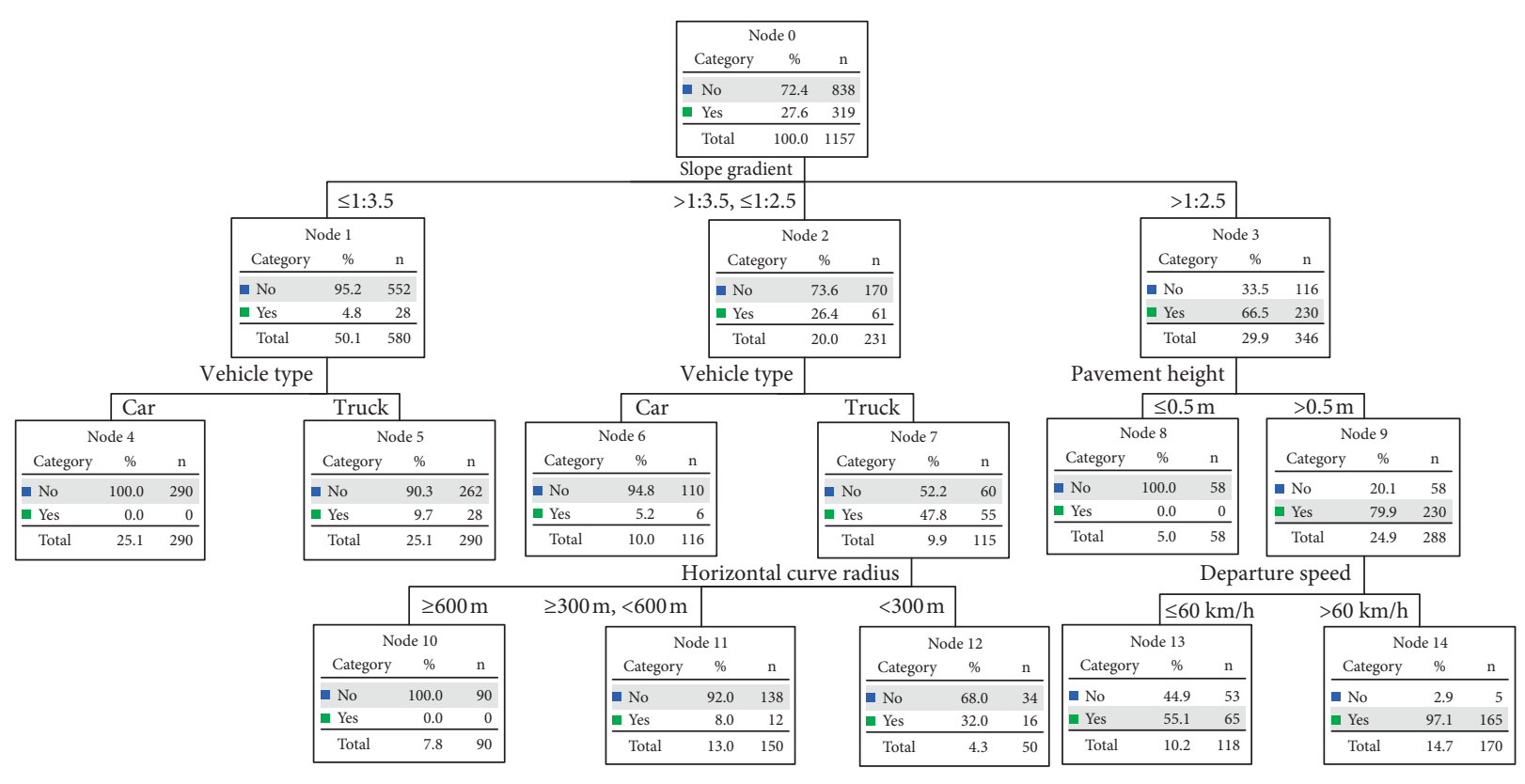

Figure 5: Decision tree model.

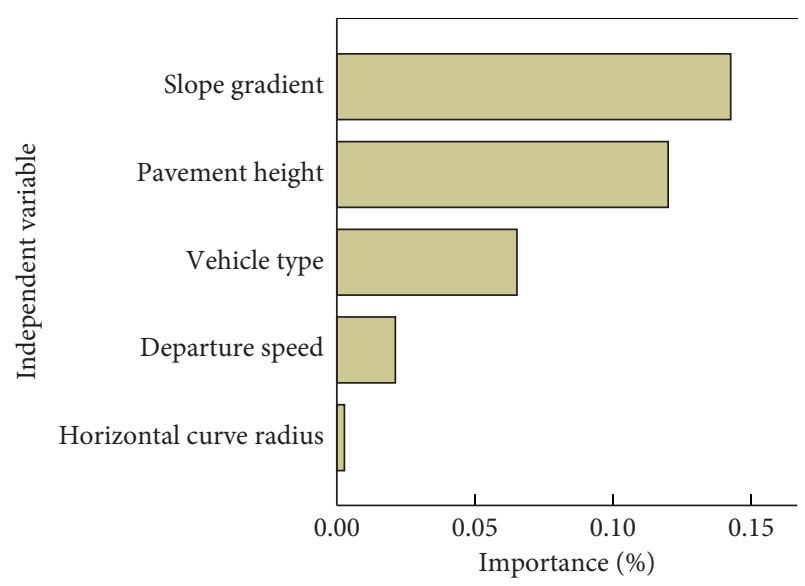

FIgURE 6: Importance of each test variable.

is, slopes where out-of-control vehicles cannot return to the road will not roll over. Next, Bayesian discriminant analysis is utilized to construct discriminant functions of vehicle motion states corresponding to different operating speeds, slope gradients, pavement heights, and horizontal curve radii for trucks and cars to determine the safe slope.

The vehicle motion states studied in this paper include rollover and nonrollover states: if $i=1$, the vehicle rolls over, and if $i=2$, the vehicle does not roll over.

Section 3.1 shows that vehicle type has a strong influence on whether a vehicle rolls over. To further explore the corresponding discriminant conditions of the motion state for different vehicle types, this paper constructs vehicle rollover and nonrollover discriminant functions separately for trucks and cars. First, the slope gradient, pavement height, departure speed, and horizontal curve radius are taken as independent variables, and the final vehicle state is taken as the classification variable; all of these variables are included in the Bayesian discriminant analysis. The proportions of data samples belonging to each category are then set as prior probabilities. Given that some of the data obtained by the simulation test may not conform to a multivariate normal distribution, the stepwise discriminant method is used for analysis. The test results for trucks and cars on the straight section and curved section are shown in Table 5.

As shown in Table 5, according to the value of lambda, the significance level of each variable varies for trucks and cars on straight and curved sections, and the slope gradient is still the most important factor affecting vehicle rollover, except in the case of trucks in a curved section. Additionally, all Sig values are equal to 0.000 , which indicates statistical significance. These results illustrate that all variables included in Bayesian discriminant analysis are highly significant to the discriminant function for both trucks and cars. Therefore, the discriminant functions of vehicle motion states constructed by the above variables have a strong discrimination ability, as follows:

(1) Discriminant function for truck rollover on the straight section:

$$
E_{11}^{\text {truck }}=-13.973+0.131 v+0.533 \alpha+0.561 h .
$$

(2) Discriminant function for truck nonrollover on the straight section:

$$
E_{21}^{\text {truck }}=-7.685+0.08 v+0.243 \alpha+0.085 h \text {. }
$$

(3) Discriminant function for truck rollover on the curved section:

$$
E_{12}^{\text {truck }}=-20.383+0.153 v+0.521 \alpha+1.154 h+0.013 R \text {. }
$$


TABLE 5: Enter/delete metrics.

\begin{tabular}{|c|c|c|c|c|c|c|c|}
\hline \multirow{3}{*}{ Vehicle type } & \multirow{3}{*}{ Road type } & \multirow{3}{*}{ Significant variable } & \multicolumn{5}{|c|}{ Wilks' lambda } \\
\hline & & & \multirow{2}{*}{ Lambda } & \multicolumn{4}{|c|}{ Exact $F$} \\
\hline & & & & Statistic & $D f 1$ & $D f 2$ & Sig \\
\hline \multirow{7}{*}{ Truck } & \multirow{3}{*}{ Straight } & Slope gradient & 0.566 & 61.782 & 1 & 79 & 0.000 \\
\hline & & Departure speed & 0.241 & 33.152 & 2 & 78 & 0.000 \\
\hline & & Pavement height & 0.013 & 29.328 & 3 & 77 & 0.000 \\
\hline & \multirow{4}{*}{ Curved } & Pavement height & 0.570 & 374.179 & 1 & 497 & 0.000 \\
\hline & & Slope gradient & 0.351 & 303.038 & 2 & 496 & 0.000 \\
\hline & & Departure speed & 0.118 & 240.553 & 3 & 495 & 0.000 \\
\hline & & Horizontal curve radius & 0.072 & 192.915 & 4 & 494 & 0.000 \\
\hline \multirow{7}{*}{ Car } & \multirow{3}{*}{ Straight } & Slope gradient & 0.562 & 60.776 & 1 & 78 & 0.000 \\
\hline & & Departure speed & 0.251 & 36.127 & 2 & 77 & 0.000 \\
\hline & & Pavement height & 0.019 & 28.421 & 3 & 76 & 0.000 \\
\hline & \multirow{4}{*}{ Curved } & Slope gradient & 0.675 & 238.763 & 1 & 496 & 0.000 \\
\hline & & Departure speed & 0.431 & 189.493 & 2 & 495 & 0.000 \\
\hline & & Pavement height & 0.206 & 145.357 & 3 & 494 & 0.000 \\
\hline & & Horizontal curve radius & 0.108 & 103.672 & 4 & 493 & 0.000 \\
\hline
\end{tabular}

(4) Discriminant function for truck nonrollover on the curved section:

$$
E_{22}^{\text {truck }}=-11.382+0.115 v+0.301 \alpha+0.349 h+0.018 R .
$$

(5) Discriminant function for car rollover on the straight section:

$$
E_{11}^{\mathrm{car}}=-23.761+0.22 v+0.685 \alpha+0.81 h
$$

(6) Discriminant function for car nonrollover on the straight section:

$$
E_{21}^{\mathrm{car}}=-10.343+0.169 v+0.395 \alpha+0.335 h .
$$

(7) Discriminant function for car rollover on the curved section:

$E_{12}^{\mathrm{car}}=-22.836+0.197 v+0.6 \alpha+0.7 h+0.011 R$.

(8) Discriminant function for car nonrollover on the curved section:

$E_{22}^{\mathrm{car}}=-9.645+0.137 v+0.364 \alpha+0.294 h+0.016 R$,

where $E$ is the discriminant function value corresponding to different vehicle motion states, $v$ is the departure speed $(\mathrm{km} / \mathrm{h}), \alpha$ is the slope gradient $\left({ }^{\circ}\right), h$ is the pavement height $(\mathrm{m})$, and $R$ is the horizontal curve radius $(m)$. A set of risk indicators is inserted into the above discriminant functions: if $E_{1}>E_{2}$, the vehicle will roll over; if $E_{1}<E_{2}$, the vehicle will not roll over.

In addition, some important information from these discriminant function coefficients can be found. For example, in contrast to functions (1) and (2), when the departure speed increases by one unit, the tendency of a truck to roll over on the straight section increases by 0.131 , while the tendency of truck nonrollover on the straight section increases by 0.08 , which indicates that increasing the departure speed tends to increase the likelihood of truck rollover. Similarly, increases in slope gradient and pavement height also generate the same effect, while increasing the horizontal curve radius decreases the possibility of rollover.

3.3. Calculation of the Safe Slope. Based on the constructed discriminant functions of vehicle motion states, this paper holds that when $E_{1}<E_{2}$, the vehicle will not roll over. Therefore, based on this, let $E_{11}{ }^{\text {truck }} \leq E_{21}{ }^{\text {truck }}$, $E_{12}{ }^{\text {truck }} \leq E_{22}{ }^{\text {truck }}, E_{11}{ }^{\text {car }} \leq E_{21}{ }^{\text {car }}$, and $E_{12}{ }^{\text {car }} \leq E_{22}{ }^{\text {car }}$. After these inequalities are sorted and simplified, safe slope calculation models corresponding to different operating speeds, pavement heights, and horizontal curve radii can be obtained, as shown in formulas (12), (13), (14), and (15), respectively.

(1) Calculation model for trucks on the straight section:

$$
\beta_{1}^{\text {truck }} \leq 24.18-0.17 v-1.64 h .
$$

(2) Calculation model for trucks on the curved section:

$$
\beta_{2}^{\text {truck }} \leq 18.91-0.17 v-3.66 h+0.023 R .
$$

(3) Calculation model for cars on the straight section:

$$
\beta_{1}^{\mathrm{car}} \leq 26.27-0.18 v-1.64 h .
$$

(4) Calculation model for cars on the curved section:

$$
\beta_{2}^{\mathrm{car}} \leq 19.89-0.25 v-1.72 h+0.021 R,
$$

where $\beta$ is the maximum safe slope $\left({ }^{\circ}\right)$ for different vehicle types and road types. 
These calculation models show that, with increases in departure speed and pavement height, the maximum safety slope should be reduced to decrease the risk of runaway vehicle rollover. Additionally, increasing the horizontal curve radius reduces the rollover possibility in the process of a vehicle turning by decreasing centrifugal force, which allows a higher safety slope to be set appropriately.

3.4. Calculation of RCZ Width. Based on the obtained safe slope corresponding to different traffic conditions and road conditions, 1,068 sets of data in which vehicles do not roll over are selected from the simulation data collected in Section 2.1. By calibrating the slope clear zone (SCZ) width, that is, the transverse horizontal distance from the right front of the vehicle to the road edge, in combination with the shoulder width, the recommended width of the RCZ based on the safe slope can be obtained, as shown in Figure 7.

According to the calibration results of the vehicle final position, the relationships between SCZ width and departure speed, safe slope gradient, horizontal curve radius, pavement height, and vehicle type are shown in Figures 8 through Figure 9. Figures 8, 10, and 11 show that SCZ width gradually increases with increasing departure speed and safe slope gradient, and the increasing trend becomes increasingly obvious; in contrast, SCZ width gradually decreases with increasing horizontal curve radius, and the decreasing trend becomes increasingly smaller. As seen in Figure 12, SCZ width gradually decreases with increasing pavement height, which can be explained by the fact that a higher pavement is more likely to lead to a vehicle rollover, which makes it impossible to obtain an effective RCZ width. Therefore, only limited calibration data can be extracted under the conditions of a flat slope and low speed. As seen in Figure 9, the distributions of the SCZ width corresponding to trucks and cars are different, indicating that the $\mathrm{RCZ}$ widths required by different vehicle types are different. Additionally, the distribution width between the two vehicle types indirectly illustrates that there are more nonrollover data for cars than for trucks. Therefore, research on RCZ width should be carried out for different vehicle types on straight and curved road sections.

Referring to the relationships between SCZ width and each test variable, this paper uses SPSS software to fit the RCZ width calculation models for trucks and cars on the straight section and curved section. By comparing the correlation coefficients $\left(R^{2}\right)$ of the different models, the following optimal calculation models are determined. The $R^{2}$ values of models (16), (17), (18), and (19) are 0.924, 0.913, 0.935, and 0.918, respectively. These models show that for both trucks and cars, RCZ width has an exponential relation with departure speed and slope gradient and has a power-law relation with pavement height and horizontal curve radius.

(1) Calculation model for trucks on the straight section:

$$
\begin{aligned}
L_{1}^{\text {truck }}= & e^{0.021 v}+2.373 e^{\left(\beta_{1}^{\text {truck }} / 25.425\right)}-149.712 h^{0.004} \\
& +147.246+w .
\end{aligned}
$$

(2) Calculation model for trucks on the curved section:

$$
\begin{aligned}
L_{2}^{\text {truck }}= & 0.938 e^{0.028 v}+3.949 \times 10^{4} e^{1.343 \times 10^{-5} \beta_{2}^{\text {truck }}} \\
& -2.872 \times 10^{-20} h^{24.392}+1.731 \times 10^{3} R^{-1.009} \\
& -3.9495 \times 10^{4}+w .
\end{aligned}
$$

(3) Calculation model for cars on the straight section:

$$
\begin{aligned}
L_{1}^{\mathrm{car}}= & e^{0.029 v}+2.872 e^{\left(\beta_{1}^{\text {car }} / 23.741\right)}-140.237 h^{0.003} \\
& +131.673+w .
\end{aligned}
$$

(4) Calculation model for cars on the curved section:

$$
\begin{aligned}
L_{2}^{\mathrm{car}}= & 2.095 e^{0.023 v}+3.950 \times 10^{4} e^{1.098 \times 10^{-5} \beta_{2}^{\text {car }}} \\
& -0.006 h^{2.832}+1.390 \times 10^{3} R^{-0.970} \\
& -3.951 \times 10^{4}+w
\end{aligned}
$$

where $L$ is the recommended RCZ width corresponding to different vehicle types and road types (m) and $w$ is the shoulder width (m).

Considering that roads host a mix of cars and trucks, this paper introduces the proportion of trucks $W$ to further obtain calculation models of the safe slope and RCZ width for different traffic compositions of straight and curved sections, as shown in models (20)-(23).

(1) Final model of the safe slope for the straight section:

$$
\alpha_{1} \leq W \times \operatorname{model}(12)+(1-W) \times \operatorname{model}(14) .
$$

(2) Final model of the safe slope for the curved section:

$$
\alpha_{2} \leq W \times \operatorname{model}(13)+(1-W) \times \operatorname{model}(15) .
$$

(3) Final model of the RCZ width for the straight section:

$$
L_{1}=W \times \operatorname{model}(16)+(1-W) \times \operatorname{model}(18) .
$$

(4) Final model of the RCZ width for the curved section: 


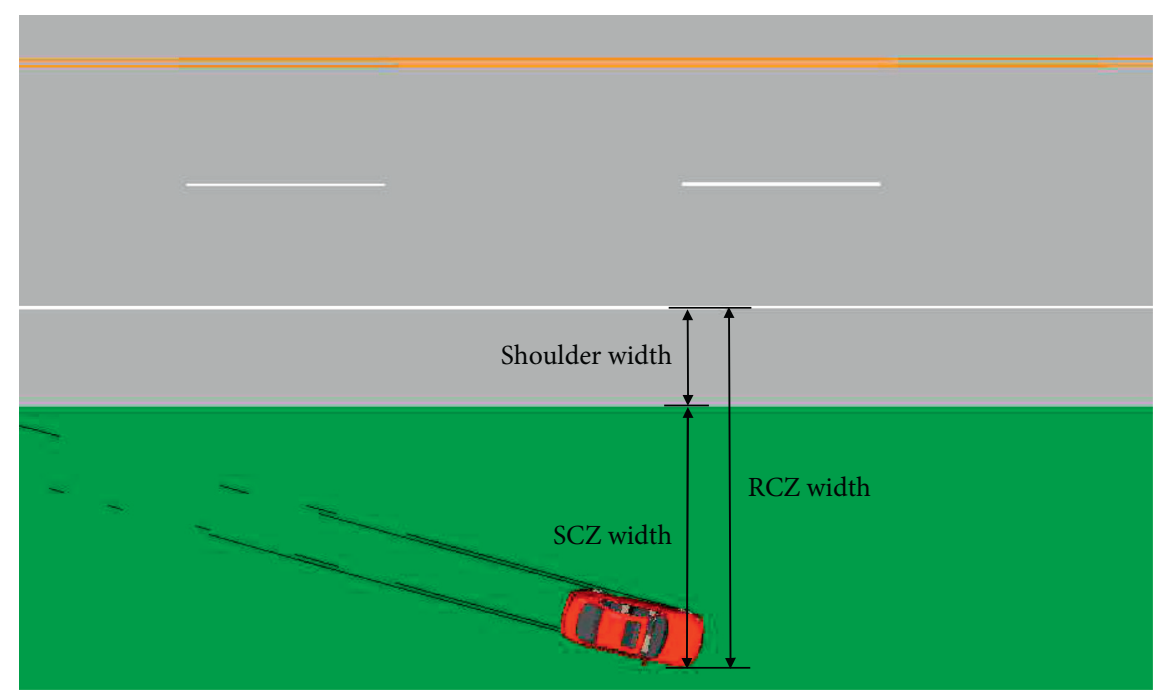

FIGURE 7: Definition of RCZ width.

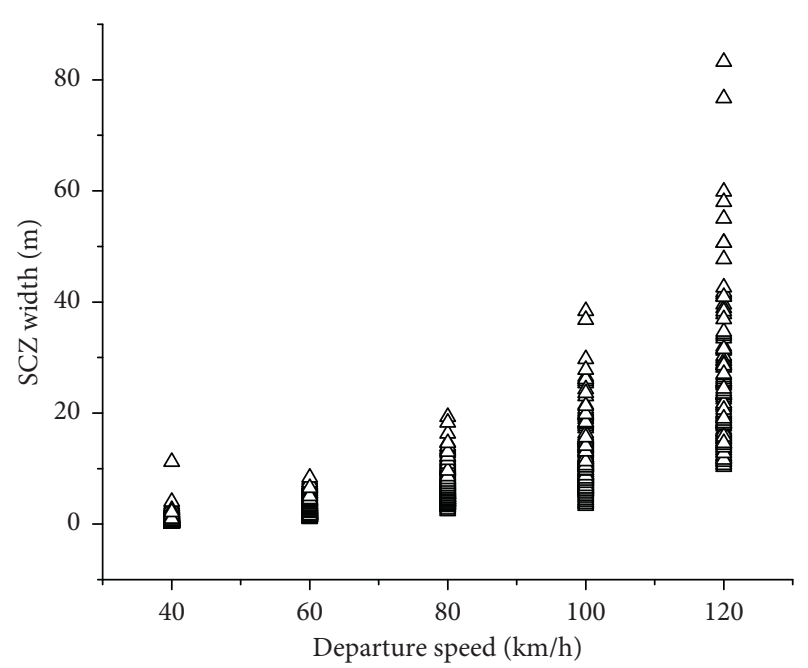

FIGURE 8: Relationship between $l$ and the departure speed.

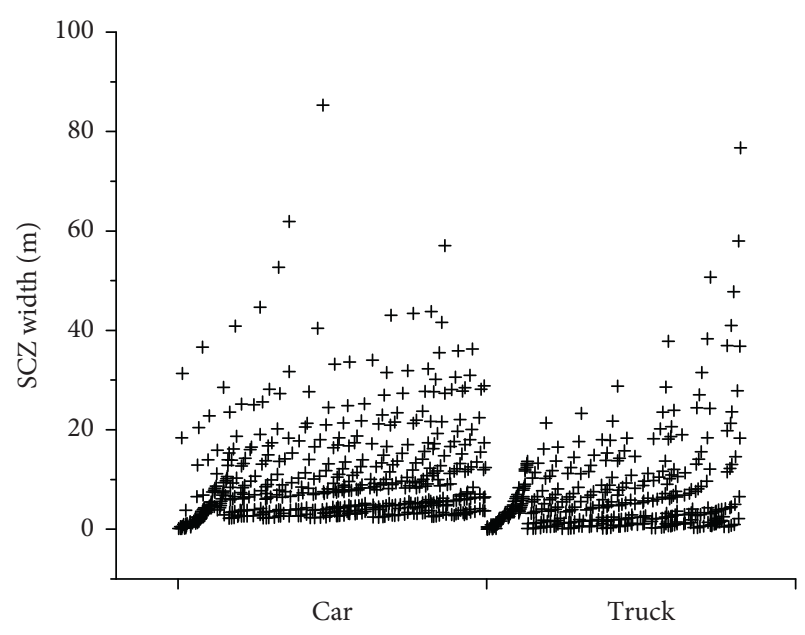

Figure 9: Distribution of $l$ among different vehicle types.

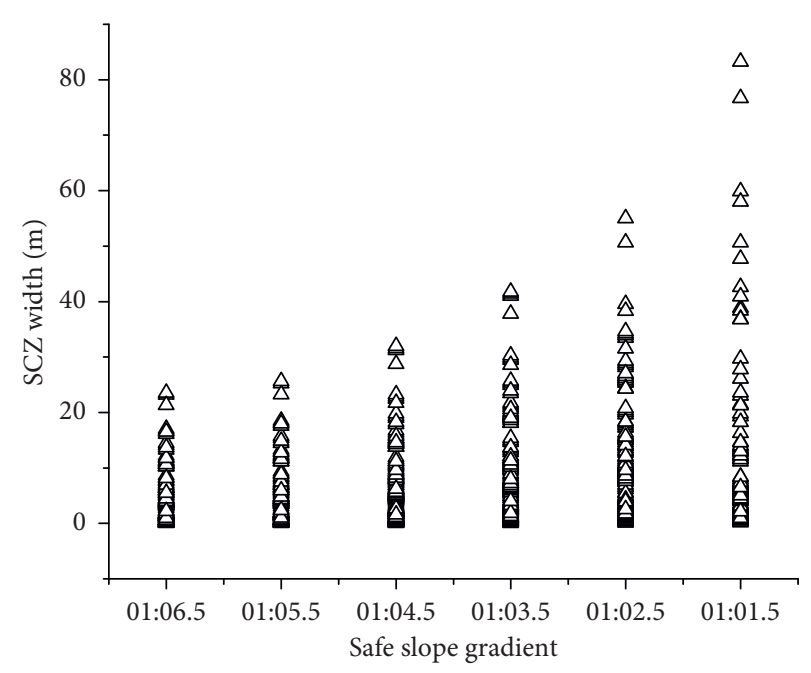

FIGURE 10: Relationship between $l$ and the safe slope gradient.

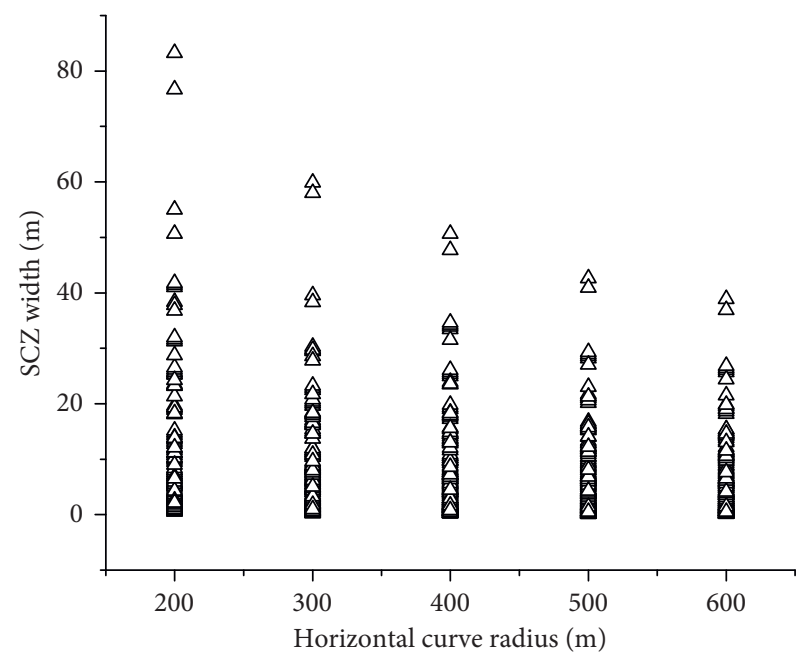

Figure 11: Relationship between $l$ and the horizontal curve radius. 


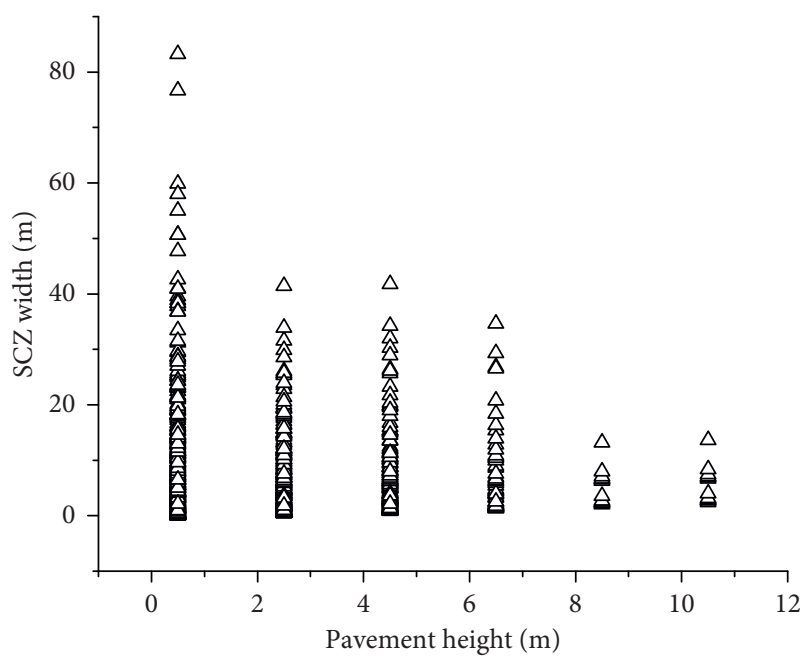

FIgURE 12: Relationship between $l$ and the pavement height.

$$
L_{2}=W \times \operatorname{model}(17)+(1-W) \times \operatorname{model}(19) .
$$

\section{Conclusion}

Considering the rollover risk of vehicles after running off the road, this paper proposes the concept of a safe slope. PCCrash simulation software is employed to carry out tests on trucks and cars exiting the road. By recording vehicle motion states (rollover or nonrollover) and motion tracks, safe slope calculation models corresponding to different operating speeds, pavement heights, and horizontal curve radii for trucks and cars are constructed. The proposed safety slope can be applied to a section with limited land area and high subgrade and ensure that vehicles entering the roadside do not roll over. The fourth edition of the $R D G$ stipulates that a slope of less than 1:4 is a recoverable slope for runaway vehicles, while China's Specifications for Highway Safety Audit (JTG B05-2015) stipulate that the slope should be less than 1:6. However, these two standards are uniform and do not consider differences in road characteristics. When vehicles run off the road, the departure speed, pavement height, horizontal curve radii, and vehicle type have important influences on their motion state. Therefore, the safe slope standards of different sections should be flexibly set according to geometric indexes, traffic characteristics, and roadside features.

The fourth edition of the $R D G$ and China's Specifications for Highway Safety Audit (JTG B05-2015) provide the RCZ width determination method. For the straight section with fill and excavation subgrades, the fourth edition of the $R D G$ provides a recommended RCZ width corresponding to different design speeds, AADT, and slope. For the curved section, it provides a correction coefficient for a curved section that is based on the horizontal curve radius. Referring to the fourth edition of the RDG, China's Specifications for Highway Safety Audit (JTG B05-2015) show how to determine the recommended RCZ width in the form of a graph. However, these two standards do not consider the pavement height and vehicle type, and the calculation accuracy of the graphical method is inadequate. Therefore, by calibrating the lateral distance from the final position of vehicles to the road edge, this paper applies multiple regression analysis to propose a method for calculating RCZ width based on the operating speed, safe slope, pavement height, horizontal curve radii, and vehicle type and realizes a method for quantitatively calculating the precise RCZ width. The designed RCZ width can provide drivers with an area that ensures that a vehicle will not roll over and will be able to stop safely. The sustainable development concept of "saving land resources" is also practiced. However, since the research results of this paper are based on simulation data, certain variables are assigned values in advance according to professional standards and experience. Validation of the results should be carried out with a series of real-world data in the future.

Additionally, given the lack of land resources and the social stability problems caused by land expropriation and demolition, it is difficult to effectively implement the acceptable roadside design in all regions. Therefore, future research should also focus on the RCZ setting conditions. For example, in urban regions with dense populations, the safety improvement benefits brought by setting a safe slope and RCZ should be calculated based on roadside accident prediction and roadside accident losses. Additionally, the extra costs generated by setting a safe slope and RCZ should be checked in terms of construction and maintenance, land use index, and social stability risk. Finally, the benefit-cost ratio should be calculated to determine whether the roadside safety design should be carried out.

\section{Data Availability}

The data used to support the findings of this study are available from the corresponding author upon request.

\section{Conflicts of Interest}

The authors declare that they have no conflicts of interest.

\section{Acknowledgments}

This study was supported by the National Key Research and Development Program of China (no. 2018YFB1600900), the National Natural Science Foundation of China (no. 51778063), the MOE Layout Foundation of Humanities and Social Sciences (no. 18YJAZH009), and the Fundamental Research Funds for the Central Universities (no. 2572019AB26).

\section{References}

[1] Federal Highway Administration (FHWA), Roadway Departure Safety, Federal Highway Administration (FHWA), Washington, DC, USA, 2018.

[2] R. Consortium, Guidelines for Roadside Infrastructure on New and Existing Roads. Roadside Infrastructure for Safer European Roads, Deliverable 6, European Commission, Brussels, Belgium, 2005. 
[3] Traffic Management Bureau of the Ministry of Public Security (TMBMPS), Road Traffic Accident Statistical Annual Report, Traffic Management Bureau of the Ministry of Public Security (TMBMPS), Beijing, China, 2018.

[4] American Association of State Highway and Transportation Officials (AASHTO), Roadside Design Guide, American Association of State Highway and Transportation Officials (AASHTO), Washington, D. C., fourth edition, 2011.

[5] C. V. Zeeger, J. Hummer, D. Reinfurt, L. Herf, and W. Hunter, "Safety effects of cross-section design for two-lane roads," FHWA and TRB, National Research Council, Washington, D.C., 1987.

[6] C. V. Zeeger and F. M. Council, Safety Effectiveness of Highway Design Features, FHWA, Design Concepts Research Division, Washington, D.C., 1992.

[7] X. Fan and Y. Xing, "Study on the width design of highway roadside clear zone considering tolerance concept," Journal of Transportation Engineering and Information, vol. 11, no. 04, pp. 49-54, 2013.

[8] Ministry of Transport of the People's Republic of China (MTPRC), Specifications For Highway Safety Audit, Ministry of Transport of the People's Republic of China (MTPRC), Beijing, China, 2015.

[9] M. Department of Transportation (MDOT), Road Design Manual, Michigan Department of Transportation (MDOT), Michigan, US, 2011.

[10] C. R. Sax, T. H. Maze, R. R. Souleyrette, N. Hawkins, and A. L. Carriquiry, "Optimum urban clear zone distance," Transportation Research Record, vol. 2195, no. 1, pp. 27-35, 2010.

[11] K. W. Ogden, Safer Roads: A Guide to Road Safety Engineering, Ashgate Publishing Company, Burlington, Vermont, 1996.

[12] D. S. Turner and T. Barnett, "Case study: Poles in the urban clear zone," Transportation Research Record, vol. 1233, pp. 155-163, 1989.

[13] T. H. Maze, C. Sax, and N. R. Hawkins, "The safety benefits added by lateral roadside clearance to urban streets," Urban Street Design \& Planning, vol. 2, pp. 11-17, 2013.

[14] J. McLean, "Review of the development of US roadside design standards," Road \& Transport Research, vol. 11, no. 2, pp. 29-37, 2002.

[15] C. Jurewicz and V. Pyta, "Effect of clear zone widths on runoff-road crash outcomes," in Proceedings of the 2010 Australasian Road Safety Research, Policing and Education Conference, pp. 1-12, Canberra, Australia, January 2010.

[16] C. D. Fitzpatrick, C. P. Harrington, M. A. Knodler Jr, and M. R. Romoser, "The influence of clear zone size and roadside vegetation on driver behavior," Journal of Safety Research, vol. 49, pp. 97-104, 2014.

[17] C. D. Fitzpatrick, S. Samuel, and M. A. Knodler Jr, "Evaluating the effect of vegetation and clear zone width on driver behavior using a driving simulator," Transportation Research Part F: Traffic Psychology and Behaviour, vol. 42, pp. 80-89, 2016.

[18] G. Cheng, R. Cheng, Y. Pei, L. Xu, and W. Qi, "Severity assessment of accidents involving roadside trees based on occupant injury analysis," PLoS One, vol. 15, no. 4, Article ID e0231030, 2020.

[19] N. Beauchamp, Analysis of a Dolly Rollover with PC-Crash, SAE International, New York, NY, USA, 2009.

[20] C. L. Naing, J. Hill, R. Thomson et al., "Single-vehicle collisions in Europe: analysis using real-world and crash-test data," International Journal of Crashworthiness, vol. 13, no. 2, pp. 219-229, 2008.

[21] Ministry of Transport of the People's Republic of China (MTPRC), Design Specification For Highway Alignment (JTG D20-2017), Ministry of Transport of the People's Republic of China (MTPRC), Beijing, China, 2017.

[22] L. Li, X. Zhu, and Z. Ma, "Driver brake reaction time under real traffic risk scenarios," Automotive Engineering, vol. 36, no. 10, pp. 1225-1229, 2014.

[23] General Administration of Quality Supervision (AQSIQ), Identification for the Speed of Vehicle Involved in Road Traffic Accident, GB/T 33195-2016, Beijing, China, 2016.

[24] C. Strobl, J. Malley, and G. Tutz, "An introduction to recursive partitioning: rationale, application, and characteristics of classification and regression trees, bagging, and random forests," Psychological Methods, vol. 14, no. 4, pp. 323-348, 2009.

[25] G. Cheng, R. Cheng, Y. Pei, and L. Xu, "Probability of roadside accidents for curved sections on highways," Mathematical Problems in Engineering, vol. 2020, Article ID 9656434, 18 pages, 2020.

[26] G. Ritschard, "CHAID and earlier supervised tree methods," Contemporary Issues in Exploratory Data Mining in the Behavioral Sciences, pp. 48-74, London, Routledge, 2013.

[27] S. Dong and J. Zhou, “A comparative study on drivers' stop/go behavior at signalized intersections based on decision tree classification model," Journal of Advanced Transportation, vol. 2020, Article ID 1250827, 13 pages, 2020.

[28] G. Prati, L. Pietrantoni, and F. Fraboni, "Using data mining techniques to predict the severity of bicycle crashes," Accident Analysis \& Prevention, vol. 101, pp. 44-54, 2017.

[29] C. Yu, SPSS Statistical Analysis, Publishing House of Electronics Industry, Beijing, China, 2007.

[30] N. Friedman, D. Geiger, and M. Goldszmidt, "Bayesian network classifiers," Machine Learning, vol. 29, no. 2-3, pp. 131-163, 1997.

[31] S. H. Lee, Y. D. Lee, and M. Do, "Analysis on safety impact of red light cameras using the Empirical Bayesian approach," Transportation Letters, vol. 8, no. 5, pp. 241-249, 2016.

[32] X. He, Multivariate Statistical Analysis (Fourth Edition), China Renmin University Press, Beijing, China, 2015. 